Obituary

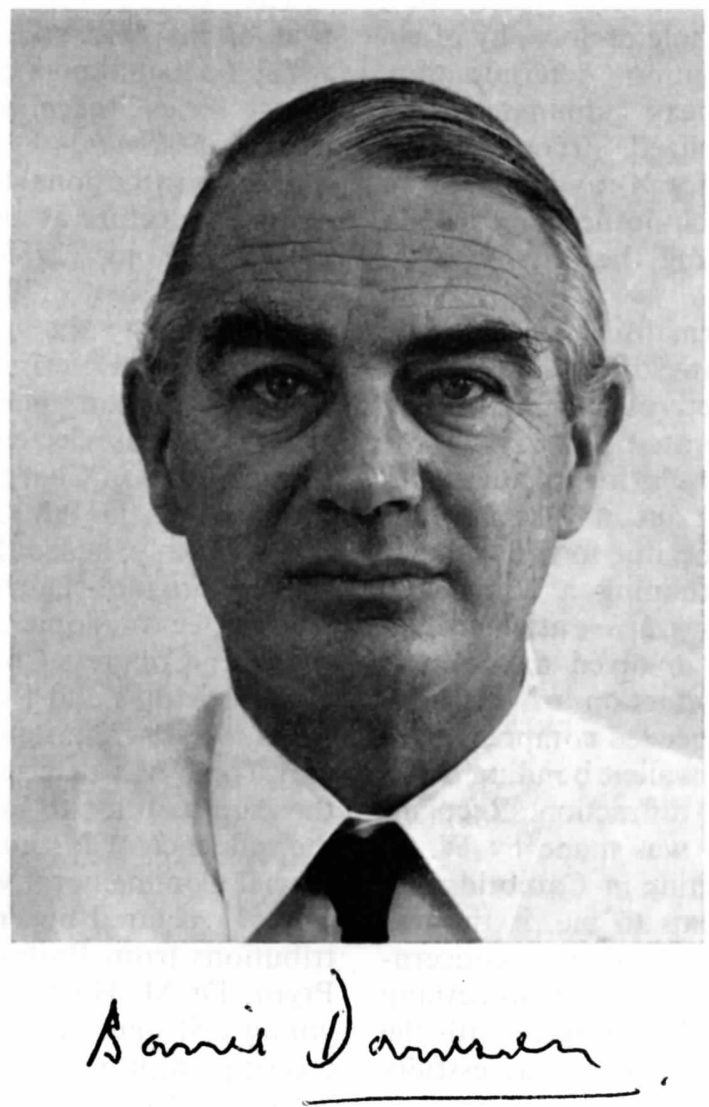

\section{Barrie Dawson}

1925 - 1974

Barrie Dawson died suddenly on 20 February 1974. Born in Melbourne he took first-class honours B.Sc and M.Sc in Chemistry at Melbourne University. Proceeding to Cambridge, he gained his $\mathrm{Ph}$. D. In 1950, he joined CSIRO in its Section (later Division) of Chemical Physics, being with the Division for the remainder of his research career. From 1968, he was a Chief Research Scientist.

The early research work of Dawson in Cambridge involved the $\mathrm{X}$-ray analysis of the complex heteropolyanion of $\mathrm{K}_{6}\left(\mathrm{P}_{2} \mathrm{~W}_{18} \mathrm{O}_{62}\right) \cdot 14 \mathrm{H}_{2} \mathrm{O}$. Carried out prior to the era of computers, it gave indications of the pertinacity and self-reliance which were characteristic of his subsequent development.

In Melbourne, he was initially involved in X-ray studies of the structures of dicarboxylic amino acids. It was while occupied with the analysis of aspartic acid hydrochloride that he came to appreciate the deficiencies and approximations of the standard methodology on which previous structure analysis had been based. One result was an investigation of the limitations of then-existing $f$ curves by comparison with those derived from the accurate poly-determinantal wave functions of S.F. Boys. Of more importance in the long term was his appreciation that, for atoms involved in chemical bond formation, their description as spherical entities was a poor approximation to the real situation. $\mathrm{He}$ was therefore led to consider the crucial question as to how best to describe, in mathematical terms, atoms in molecules so as to achieve a realistic approximation to their chemical and physical features. At this period (1953-60), this question lay outside the mainstream of prevailing practice.

A major achievement of Dawson, therefore, was his recognition and demonstration that the charge density and vibrational attributes of an atom must reflect the local symmetry of its environment - with the consequent need for atomic functions whose non-centrosymmetric character transcended the centrosymmetric restrictions of standard postulates of that era. $\mathrm{He}$ introduced the concept of anti-symmetry to describe his generalized atomic scattering function in all essential details.

The introduction of the anti-symmetry concept for dealing with non-centrosymmetric atomic properties necessitated important modifications to procedures previously regarded as adequate. Thus, numerical examination of non-spherical X-ray scattering effects associated with directed 'lone pairs' in $\mathrm{N}, \mathrm{O}$ and $\mathrm{F}$ (1964) provided a vivid demonstration of the way in which major errors were introduced when centrosym- 
metric restrictions were maintained. This work had a fundamental impact upon the whole philosophy of accurate X-ray electron distribution determination. Further development of his ideas culminated in a definitive paper on his generalized structure-factor formalism (1967). Equally valid for X-ray and neutron situations, it provided the much-needed integration of the two situations, highlighting the differences as well as the similarities.

The fact that Dawson's formalism was soundly based physically was demonstrated by its application to classical problems of the structures of crystal chemistry, for example, to the celebrated problem of the so-called 'forbidden' $222 \mathrm{X}$-ray reflexion of diamond. Since W. H. Bragg first pointed out in 1921 that the existence of this reflexion must be due to the shape of the atom itself, progress in attaining a convincing explanation had been slow. Various ad hoc attempts had been made but these had not involved any radical change in approach. The introduction of the antisymmetry concept provided the needed comprehensive and elegant explanation of the covalent bonding detail in diamond accessible by X-ray diffraction. Recognition of this major step forward was made by W. L. Bragg at the Inter-Congress Meeting in Cambridge in 1968, when he said 'This, it seems to me, is the fine flowering of the first phase of the calculations concerning an atom which we thought we knew something about, making the result of calculation agree with the observations'. The approach was extended successfully to silicon and germanium.

The versatility of Dawson's formulation has also been demonstrated conclusively in the case of neutron diffraction studies of compounds with the fluorite structure. The question of high physical interest in this case concerns anharmonic vibration, the phenomenon implicit in thermal expansion but otherwise lying outside the standard vibrational postulate. Dawson's antisymmetric arguments in this case applied to the anions of fluorite compounds, allowed him to predict significant inequivalence between certain pairs of neutron reflections which, if treated in terms of the standard postulate, should be exactly equivalent. He showed such inequivalence as consistent with hitherto puzzling anomalies in neutron evidence from $\mathrm{UO}_{2}$ and $\mathrm{CaF}_{2}$ and developed theory for predicting the variation of this inequivalence with rising temperature. His predictions were subsequently confirmed in all essential detail by precise neutron-diffraction experiments carried out at Harwell on $\mathrm{BaF}_{2}, \mathrm{SrF}_{2}$ and $\mathrm{CaF}_{2}$. Analysis in terms of his formalism has yielded valuable insights into the nature of the one-particle potential functions relevant to Bragg experimentation on these compounds and subsequently to anharmonic vibrational effects in the classic zincblende structures. Later work on compounds of the latter type, based on Dawson's formalism, reveals that they manifest a subtle form of Friedel inequality of a type unaccountable in terms of spherical atoms.
The breadth of his interests and his critical appreciation of his field are evident in the extensive review which he had almost completed and which will appear in the series Advances in Structure Research by Diffraction Methods.

His contributions to the subject led to his being invited to lecture at and participate in the IUCr Congresses at Rome (1963), Moscow (1966), Stony Brook (1969) and Kyoto (1972). He gave the opening 'keynote' lecture to the specialist Inter-Congress Meeting on 'Accurate Determination of X-ray Intensities and Structure Factors' held in Cambridge, U.K., in June, 1968, and was elected a member of the Ad Interim Commission on Charge, Spin and Momentum Density proposed at the 9th General Assembly at Kyoto. At this Assembly, he led the delegation from Australia. He was the original chairman of the Scientific Programme Committee for Topic 1 - 'Real Atoms in Crystals' - of the Inter-Congress Conference on 'Diffraction Studies of Real Atoms and Real Crystals' held in Melbourne, Australia, 19-23 August 1974. The essential format of that Topic was determined by his strenuous efforts in the months prior to his death and its success reflected the influence of his guiding hand. With his passing, a special Commemorative Session was incorporated into Topic 1, chaired by Professor N. Kato and with contributions from Professor F. N. Hirshfeld, Dr A. W. Pryor, Dr M. Hart, Dr K. V. J. Kurki-Suonio and a young colleague, Dr C. Howard. With Dawson's increasing stature in his field, his contributions to the activities of the Union could only be expected to have grown.

Owing to his individual approach to his work and the fundamental nature of the questions he set himself to answer, Dawson's output in the crude terms of numbers of publications was not prolific. Of greater significance is the influence which his work exerted on others. His seminal contributions to the interpretation of anharmonic effects have been mentioned. His studies on silicon have stimulated the most sophisticated X-ray and neutron diffraction experiments in the U.K., U.S.A. and Japan - to establish highly accurate absolute structure factor values from Pendellösung measurements, to detect 'forbidden' neutron reflexions and to study the latter as a function of temperature. Dawson's ideas of the role of local symmetry have been extended to the study of small organic molecules. With the passage of the years, it seems clear that the influence of his ideas will grow and much derivative work will demonstrate the elegance and validity of his approach and confirm the soundness of his chemical and physical insight.

Barrie Dawson will be sorely missed not only by his colleagues in Australia but also by those in other parts of the world, colleagues whom he impressed by his clear thinking, his self-reliance, his complete dedication to and grasp of his subject as well as by his charm and friendliness.

A. McL. MAthieson 